\title{
Childhood traumas and suicide probability in obsessive-compulsive disorder patients with and without suicide attempts
}

\author{
Faruk Kilic $^{1 \oplus}$, Arzu Azime Unlu Karakoc ${ }^{2 \oplus}$, Umit Isik $^{3 \oplus}$, Feyza Donmez ${ }^{1 \oplus}$, Arif Demirdas ${ }^{1 \odot}$ \\ 'Suleyman Demirel University, Faculty of Medicine, Department of Psychiatry, Isparta - Turkey \\ 2Elazig Mental Health Hospital, Department of Psychiatry, Elazig - Turkey \\ ${ }^{3}$ Suleyman Demirel University, Faculty of Medicine, Department of Child and Adolescent Psychiatry, Isparta - Turkey
}

\begin{abstract}
Objective: The aim of this research is to determine the differences in childhood traumas and the probability of suicide in obsessive-compulsive disorder (OCD) patients with and without suicide attempts.

Method: Sixty-five OCD patients without suicide attempt history and 39 OCD patients with a history of suicide attempts were included in the study. To measure the clinical variables The Childhood Trauma Questionnaire (CTQ), Suicide Probability Scale, Yale-Brown Obsessive-Compulsive Scale and Beck Depression Inventory were applied.

Results: We found that the OCD group with suicide attempts was significantly higher than the OCD group without a suicide attempt due to emotional neglect, physical neglect, sexual abuse, and CTQ total scores. Aggression and sexual obsessions were higher in the OCD group who has attempted suicide. Obsessive-compulsive symptoms, depression and insight scores of OCD patients with suicide attempts were worse than OCD patients without suicide attempts. Also, correlations were observed between childhood traumas and suicidal probability scores.

Conclusion: This study showed that childhood traumas may be a contributing factor to suicide probability and attempt in patients with OCD. Moreover, this study reveals that the current probability of suicide is a higher risk in OCD patients who had previously attempted suicide in the past.
\end{abstract}

Keywords: Childhood trauma, lifetime suicide attempt, obsessive-compulsive disorder, suicide

\section{INTRODUCTION}

Obsessive-compulsive disorder (OCD) is a psychiatric disorder that usually follows a recurring pattern with repetitive obsessions and compulsions with functional impairment and worsening quality of life. OCD is the sixth most common mental disorder with a lifetime prevalence of $2.5 \%$ reported in the general population (1).
When left untreated, obsessions and compulsions cause considerable distress to be time-consuming and have a significant negative impact on the sufferer's interpersonal relationships and career, often resulting in isolation. Given the significant prevalence of OCD, its costs, its related impairments and its potential of lowering the quality of life, $38 \%$ to $89 \%$ of OCD patients do not seek or receive treatment for their symptoms (2-4).

How to cite this article: Kilic F, Unlu Karakoc AA, Isik U, Donmez F, Demirdas A. Childhood traumas and suicide probability in obsessive-compulsive disorder patients with and without suicide attempts. Dusunen Adam The Journal of Psychiatry and Neurological Sciences 2020;33:402-409.

Correspondence: Faruk Kilic, Assistant Professor, Suleyman Demirel University Medicine Faculty, Department of Psychiatry, 32260 Isparta - Turkey 
Childhood traumas have been associated with significant neurobiological changes and are linked to several long-term harmful effects, including an increased risk of developing mental disorders such as posttraumatic stress, depressive, and anxiety disorders (5-8). In addition to these disorders, several studies have shown that OCD characterized by ego-dystonic, disturbing recurrent, anxiety-causing thoughts and repetitive behaviors or mental actions may be associated with childhood trauma (9-11). Brander et al. (11) showed that childhood traumas were a risk factor for OCD. Carpenter and Chung (12) found a higher rate of emotional neglect, emotional abuse, physical neglect, and physical abuse in OCD patients compared to controls. Caspi et al. (13) suggested a positive association between contact childhood sexual abuse and OCD.

Childhood traumas are also one of the main risk factors for suicide attempts (14). Maltreatment during the early stages of a person's development, increases the risk of suicidal behaviors by two to five times during their lifetime (15). In people with suicide attempts, suicidal ideation is triggered more easily than those without it (16). Recent studies have found that suicidal behavior is much more common in patients with OCD than previously claimed (17-19). Dell'Osso et al. (20) found that OCD has a lifelong risk of suicide attempt at a rate of 14.6. Although several studies suggest that the idea of suicide is related to the clinical and demographic factors, there are few studies simultaneously evaluating the relationship between suicide attempts and childhood traumas and clinical features including insight in OCD patients $(18,21)$. Considering the substantial burden generated by the relationship between OCD and suicide, there is a significant need to identify potential risk factors that can be addressed in the later approaches and treatments for prevention. To our knowledge, this is the first study comparing childhood traumas and suicide probability in OCD with and without suicide attempts.

The aim of this research is to determine the differences between OCD patients with a history of suicide and, OCD patients without such a history in the childhood traumas, suicide probability, and clinical features of.

\section{METHOD}

\section{Participants}

Sixty-five OCD patients without a history of suicide attempts and 39 OCD patients with a history of suicide attempts were included in the study. Patients were included non-consecutively. The patients were asked about their past suicide attempts, during the sociodemographic assessment. A suicide attempt was defined as the occurrence of self-directed injurious actions with the intention to end one's own life. The participants were recruited from Suleyman Demirel University Medicine Faculty, Department of Psychiatry and Elazig Mental Health and Diseases Hospital. Patients had to meet the DSM-IV-TR criteria for OCD to be included in the study. The demographic and clinical data of the patients were collected during the psychiatric interview focusing on their sociodemographic features, clinical characteristics, and OCD and other psychiatric disorders diagnosed on the basis of the DSM-IV-TR. Well-trained psychiatrists rated all of the objective measures. Volunteers who were literate and between the ages of 18-65 were included in the study. Patients with mental retardation, schizophrenia, and other psychotic disorders, systemic or neurological disorder that could impair cognitive ability were not included.

\section{Procedure}

Each participant was given the necessary time for a psychiatric interview and for filling out the sociodemographic data form and measurement instruments completely. The interviewer explained the points that were not understood by the participants. The study project was approved by Suleyman Demirel University Faculty of Medicine Clinical Research Ethical Committee and informed consent was obtained from all participants after the study was fully explained to them (Date: $21 / 03 / 2018$, Number: 71 ).

\section{Measures}

\section{Sociodemographic Data Form}

This is the question form produced by the researchers used study to assess the participants 'sociodemographic features in this study.

Yale-Brown Obsessive-Compulsive Scale (Y-BOCS): This scale was developed by Goodman et al. (22) to evaluate the characteristics and severity of the symptoms seen in patients with OCD. It consists of 19 items in total, but the first 10 items are used to determine the total score. The Y-BOCS total score is the sum of these first 10 items. The first five items indicate the obsession score and the second five items indicate the compulsion score. By adding obsession and compulsion subscale scores, a maximum of 40 points in total can be reached. The validity and reliability of the 
Turkish version of the scale were analyzed by Tek et al. (23), showing excellent inter-rater reliability for the Turkish version of the Y-BOCS. We performed a clinical assessment to evaluate the patient's insight levels. The insight levels were rated according to the YBOCS. The insight measure in YBOCS consists of 1 item. Categories 0,1 , and 2 of the YBOCS insight analysis were defined as 'good insight', and categories 3 , and 4 were defined as 'poor insight' (24).

Beck Depression Inventory (BDI): The questionnaire is a multiple-choice self-report with 21 questions measuring the severity of depression. It is based on Likert scoring ( 0 to 3 ). The score range of the inventory is 0 to 63 (25).

Childhood Trauma Questionnaire (CTQ): The 28 -item CTQ was used to assess the frequency and severity of different types of recalled childhood interpersonal trauma. The items are divided into 5 subscales: emotional abuse, physical abuse, sexual abuse, emotional neglect, and physical neglect. This scale has been developed by Bernstein et al. (26) It was adapted to Turkish by Sar et al. (27) In the adaptation, validity and reliability study of the 28-question form of the scale, it was proposed as a cut-off point of over 5 points for sexual and physical abuse, over 7 points for physical neglect and emotional abuse, over 12 points for emotional neglect, and over 35 points for the total score (27).

Suicide Probability Scale (SPS): The scale was developed by Cull and Gill (28). The Turkish adaptation, validity, and reliability studies were conducted by Atli et al. (29) The SPS consists of 36 statements. These statements are graded on a fourpoint scale according to how often they feel the statement is true for them (ranging from 'none or a little' to 'often or always'). The scale consists of four sub-dimensions: hopelessness, suicidal ideation, hostility, and negative self-evaluation. SPS is a selfreport method of 36 items that assess suicide risk. The higher scale ratings indicate a higher probability of suicide.

\section{Statistical Analysis}

SPSS for Windows version 20.0 was used for statistical analysis. The mean and standard deviation values were presented as descriptive analyzes. Normal distribution was assessed using the Kolmogorov-Smirnov test. The socio-demographic characteristics of the groups were compared using chi-square, Mann-Whitney U test, and t-test. Pearson and Spearman correlation test was examined in the relationships between parametric numerical variables. Partial correlations were performed to examine the relationship between CTQ dimensions and OCD symptom dimensions with suicidal ideation. In all analyses, the significance level was accepted as $\mathrm{p}<0.05$.

\section{RESULTS}

OCD patients were grouped into suicide attempters and non-attempters. A comparison of these two groups in terms of some sociodemographic characteristics is presented in Table 1. As shown in Table 1, there was no difference in age, sex, marital status, educational level, and working status among participants between the two groups; however, when comparing smoking and alcohol use, there was higher suicide attempters than those non-attempters $(p<0.05)$. In terms of onset of the disorder, suicide attempters had an earlier onset than non-attempters (non-attempters: $21.7 \pm 6.8$ years; suicide attempters: $18.6 \pm 3.2$ years; $\mathrm{t}=3.132, \mathrm{p}=0.002$ ). All patients were under drug medication. There was no difference between the two groups with respect to the duration of the disorder (non-attempters: $10.4 \pm 8.0$ years; suicide attempters: $12.2 \pm 8.3$ years; $t=-1.080$, $\mathrm{p}=0.283)$. Of the 39 OCD patients with suicide attempts, $27(69.2 \%)$ used the self-poisoning method, 5 (12.8\%) used the cutting method, 4 (10.3\%) used the hanging method, and 3 (7.7\%) used the jumping from a heigh method. Patients with suicide attempts had scored higher in BDI and YBOCS scores $(\mathrm{t}=-4.376, \mathrm{p}<0.001$; $\mathrm{t}=-4.102, \mathrm{p}<0.001$ respectively) than without attempt. There was statistically significant difference between the two groups with respect to the YBOCS insight scores (non-attempters scores $1.23 \pm .80$, suicide attempters scores $1.87 \pm .76, \mathrm{z}=-3.569, \mathrm{p}<0.001)$. There were 3 individuals (4.6\%) in non-attempters, and 9 individuals (23.1\%) in suicide attempters who were assessed as having poor insight and claimed that their thoughts or behaviors were not unreasonable or excessive. The poor insight rate was significantly higher than in suicide attempters than non-attempters $\left(\chi^{2}=8.139, \mathrm{p}=0.009\right)$ (Table 1$)$.

Two groups were compared In terms of obsessivecompulsive symptoms,. Aggression $\left(\chi^{2}=5.042, \mathrm{p}=0.042\right)$ and sexual $\left(\chi^{2}=3.942, p=0.047\right)$ obsessions were higher in the patients with suicide attempt. There was no statistically significant difference between the two groups in terms of compulsions (Table 2).

The results revealed higher scores for patient with suicide attempt on emotional neglect $(t=-2.589$, $\mathrm{p}=0.010)$, physical neglect $(\mathrm{t}=-2.119, \mathrm{p}=0.034)$, sexual 
Table 1: Demographic and clinical characteristics of OCD patients with or without lifetime suicide attempt

\begin{tabular}{|c|c|c|c|c|c|c|}
\hline & $\begin{array}{c}\text { Total } \\
\text { sample } \\
(n=104)\end{array}$ & $\begin{array}{l}\text { OCD patients } \\
\text { without a } \\
\text { history of } \\
\text { suicide attempt } \\
(n=65)\end{array}$ & $\begin{array}{c}\text { OCD } \\
\text { patients with } \\
\text { a history of } \\
\text { suicide attempt } \\
(n=39)\end{array}$ & $t / z / \chi^{2}$ & df & $\mathbf{p}$ \\
\hline Age & $31.6 \pm 9.7$ & $32.2 \pm 10$ & $30.8 \pm 9.2$ & $-0.602^{b}$ & - & 0.547 \\
\hline \multicolumn{7}{|l|}{ Sex } \\
\hline Male/Female & $39 / 65$ & $27 / 38$ & $12 / 27$ & $1.206^{c}$ & 1 & 0.272 \\
\hline \multicolumn{7}{|l|}{ Marital status } \\
\hline Single/Married & $50 / 54$ & $30 / 35$ & $20 / 19$ & $0.257^{c}$ & 1 & 0.612 \\
\hline \multicolumn{7}{|l|}{ Educational level } \\
\hline Primary/High/University & $21 / 37 / 46$ & $14 / 21 / 30$ & $7 / 16 / 16$ & $0.821^{c}$ & 2 & 0.663 \\
\hline \multicolumn{7}{|l|}{ Smoking habit } \\
\hline Smoker/Nonsmoker & $45 / 59$ & $21 / 44$ & $24 / 15$ & $8.485^{c}$ & 1 & 0.004 \\
\hline \multicolumn{7}{|l|}{ Alcohol consumption } \\
\hline Yes/No & $11 / 93$ & $3 / 62$ & $8 / 31$ & $6.513^{c}$ & 1 & 0.011 \\
\hline \multicolumn{7}{|l|}{ Occupational status } \\
\hline Student/Working/Not working & $26 / 34 / 44$ & $17 / 20 / 28$ & $9 / 14 / 16$ & $0.313^{c}$ & 2 & 0.855 \\
\hline Age-of-onset of disorder onset & $20.5 \pm 5.9$ & $21.7 \pm 6.8$ & $18.6 \pm 3.2$ & $3.132^{\mathrm{a}}$ & 97.904 & 0.002 \\
\hline YBOCS & $21.9 \pm 6.1$ & $20 \pm 4.8$ & $25.1 \pm 6.8$ & $-4.102^{a}$ & 102 & $<0.001$ \\
\hline BDI & $14.9 \pm 6.2$ & $13 \pm 5.2$ & $18.1 \pm 6.6$ & $-4.376^{a}$ & 102 & $<0.001$ \\
\hline Insight & $1.47 \pm 0.84$ & $1.23 \pm 0.80$ & $1.87 \pm 0.76$ & $-3.569^{b}$ & - & $<0.001$ \\
\hline \multicolumn{7}{|l|}{ Insight } \\
\hline Good/Poor & $92 / 12$ & $62 / 3$ & $30 / 9$ & $8.139^{c}$ & 1 & 0.004 \\
\hline
\end{tabular}

OCD: Obsessive-Compulsive Disorder; YBOCS: Yale-Brown Obsessive Compulsive Scale; BDI: Beck Depression Inventory.

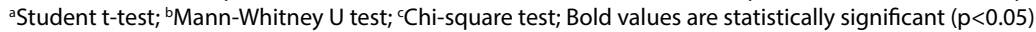

abuse $(\mathrm{t}=-2.626, \mathrm{p}=0.009)$ and CTQ total scores $(\mathrm{t}=-$ 3.313, $\mathrm{p}=0.001)$ compared to patients without attempt. In all 63 patients with OCD, childhood maltreatment was reported based on their CTQ total score. 31 (47.7\%) of the patients without suicide attempt and $32(82.1 \%)$ of with suicide attempt reported childhood maltreatment (Table 3).

Considering the distribution of childhood traumas experienced by all patients with OCD, it was observed that $40.4 \%$ experienced physical neglect, $44.2 \%$ experienced emotional neglect, $33.7 \%$ experienced physical abuse, $43.3 \%$ experienced emotional abuse and $27.9 \%$ experienced sexual abuse. Emotional neglect (36.9\%) and emotional abuse (36.9\%) were the most frequent type of maltreatment in non-attempters, followed by physical neglect (32.3\%), physical abuse $(30.8 \%)$, and sexual abuse (18.5\%). However, in suicide attempters, emotional neglect $(56.4 \%)$ was the most frequent type of maltreatment, followed by physical neglect (53.8\%), emotional abuse (53.8\%), sexual abuse
(43.6\%) and physical abuse (38.5\%). There was a significantly higher physical neglect and sexual abuse in suicide attempter patients $\left(\chi^{2}=4.697, \mathrm{p}=0.030 ; \chi^{2}=7.654\right.$, $\mathrm{p}=0.006$ respectively). Regarding gender, there was no difference in the prevalence of childhood trauma ( $\mathrm{p}>0.05)$.

Two groups were compared in terms of total suicide probability scores and their subscales, Total suicide probability scale scores and subscales scores were significantly higher in patients with suicide attempts $(\mathrm{p}<0.05)$ (Table 3).

A positive correlation was detected between the SPS score and the scores of emotional neglect $(r=0.195$, $\mathrm{p}=0.047)$, emotional abuse $(\mathrm{r}=0.362, \mathrm{p}<0.001)$, sexual abuse $(r=0.410, p<0.001)$, YBOC $(r=0.256, p=0.009)$, BDI $(\mathrm{r}=0.320, \mathrm{p}=0.001)$ and insight $(\mathrm{r}=0.294, \mathrm{p}=0.002) . \mathrm{A}$ partial correlation was conducted to assess the effects of childhood traumas on the probability of suicide independent of depression, YBOC, and insight. It was found that a mild correlation between emotional abuse 
Table 2: Distribution of obsessions and compulsions of OCD patients with or without lifetime suicide attempt

\begin{tabular}{|c|c|c|c|c|c|}
\hline & $\begin{array}{l}\text { OCD patients } \\
\text { without a } \\
\text { history of } \\
\text { uicide attempt } \\
\text { (n=65) (\%) }\end{array}$ & $\begin{array}{l}\text { OCD patients } \\
\text { with a history } \\
\text { of suicide } \\
\text { attempt } \\
(n=39)(\%)\end{array}$ & $\chi^{2}$ & df & $\mathbf{p}$ \\
\hline \multicolumn{6}{|l|}{ Obsessions* } \\
\hline Contamination & $33(50.8)$ & $21(53.8)$ & 0.092 & 1 & 0.761 \\
\hline Doubt & $29(44.6)$ & $18(46.2)$ & 0.023 & 1 & 0.879 \\
\hline Aggression & $6(9.2)$ & $10(25.6)$ & 5.042 & 1 & 0.025 \\
\hline Sexual & $7(10.8)$ & $10(25.6)$ & 3.942 & 1 & 0.047 \\
\hline Religious & $7(10.8)$ & $8(20.5)$ & 1.875 & 1 & 0.171 \\
\hline Symmetry & $6(9.2)$ & $5(12.8)$ & 0.332 & 1 & 0.564 \\
\hline Others & $6(9.2)$ & $4(10.3)$ & 0.030 & 1 & 0.864 \\
\hline \multicolumn{6}{|l|}{ Compulsions* } \\
\hline Cleaning & 33 50.8) & $22(56.4)$ & 0.311 & 1 & 0.577 \\
\hline Control & $29(44.6)$ & $17(43.6)$ & 0.010 & 1 & 0.919 \\
\hline Ritualistic & $7(10.8)$ & $5(12.8)$ & 0.100 & 1 & 0.751 \\
\hline Counting & $7(10.8)$ & $9(23.1)$ & 2.836 & 1 & 0.092 \\
\hline Arrangement & $5(7.7)$ & $8(20.5)$ & 3.663 & 1 & 0.056 \\
\hline Others & $9(13.8)$ & $4(10.3)$ & 0.287 & 1 & 0.592 \\
\hline
\end{tabular}

OCD: Obsessive-Compulsive Disorder, *Distribution of obsessions and compulsions were determined using the Yale-Brown Obsessive-Compulsive Scale (Y-BOCS) symptom checklist. $\chi^{2}$ : Chi-square test

Table 3: Comparison of OCD patients with or without lifetime suicide attempt in terms of the Childhood Trauma Questionnaire and Suicide Probability Scale

\begin{tabular}{|c|c|c|c|c|c|}
\hline & $\begin{array}{l}\text { OCD patients } \\
\text { without a } \\
\text { history of } \\
\text { suicide attempt } \\
(n=65)\end{array}$ & $\begin{array}{l}\text { OCD patients } \\
\text { with a history } \\
\text { of suicide } \\
\text { attempt } \\
(n=39)\end{array}$ & $t / z / \chi^{2}$ & df & $\mathbf{p}$ \\
\hline CTQ total & $36.9 \pm 8.1$ & $42.6 \pm 9.2$ & $-3.313^{a}$ & 102 & 0.001 \\
\hline Emotional neglect & $10.9 \pm 3.8$ & $13.3 \pm 4.3$ & $-2.589^{b}$ & - & 0.010 \\
\hline Physical neglect & $7.0 \pm 2.0$ & $7.7 \pm 2.0$ & $-2.119^{b}$ & - & 0.034 \\
\hline Emotional abuse & $7.6 \pm 2.5$ & $8.8 \pm 3.5$ & $-1.612^{b}$ & - & 0.107 \\
\hline Physical abuse & $5.6 \pm 1.1$ & $5.8 \pm 1.3$ & $-0.989^{b}$ & - & 0.323 \\
\hline Sexual abuse & $5.7 \pm 1.8$ & $6.7 \pm 2.8$ & $-2.626^{b}$ & - & 0.009 \\
\hline SPS total & $70.8 \pm 14.9$ & $88.1 \pm 15.5$ & $-4.968^{b}$ & - & $<0.001$ \\
\hline Hopelessness & $25.2 \pm 7.5$ & $30.8 \pm 7.1$ & $-3.727^{a}$ & 102 & $<0.001$ \\
\hline Negative self evaluation & $20.4 \pm 5.2$ & $23.3 \pm 4.5$ & $-2.894^{\mathrm{a}}$ & 102 & 0.005 \\
\hline Hostility & $12.9 \pm 3.2$ & $16 \pm 3.5$ & $-4.576^{a}$ & 102 & $<0.001$ \\
\hline Suicide ideation & $12.2 \pm 3.4$ & $17.8 \pm 6.9$ & $-4.300^{b}$ & - & $<0.001$ \\
\hline CTQ > 35 & 31 (47.7\%) & $32(82.1 \%)$ & $12.049^{c}$ & 1 & 0.001 \\
\hline
\end{tabular}

OCD: Obsessive-Compulsive Disorder; CTQ: Childhood Trauma Questionnaire; SPS: Suicide Probability Scale.

aStudent t-test; ${ }^{b}$ Mann-Whitney $\mathrm{U}$ test; ${ }^{\mathrm{c} C h i-s q u a r e}$ test

$(\mathrm{r}=0.354, \mathrm{p}<0.001)$, sexual abuse $(\mathrm{r}=0.354, \mathrm{p}<0.001)$ and CTQ total score $(\mathrm{r}=0.305, \mathrm{p}=0.002)$ remained independently of BDI, YBOC and insight scores. The correlation with emotional neglect disappeared $(r=0.110$, $\mathrm{p}=0.274)$. In addition, a positive correlation was detected between insight and SPS scores $(r=0.294, \mathrm{p}=0.002)$. 


\section{DISCUSSION}

The primary objective of the study is to determine the differences in childhood traumas, suicide probability, and clinical features of OCD patients with and without suicide history. One of the interesting findings is the higher scores of physical neglect, emotional neglect, sexual abuse and CTQ total scores among OCD patients with a suicide history compared to OCD patients without suicide attempts. Aggressive and sexual obsessions were also observed to be more common in this group. Another important finding is that obsessivecompulsive symptoms, depression and insight scores of the suicide attempters are worse than the nonattempters. The correlation between childhood traumas and suicide probability scores have also been observed.

The results of this study revealed that childhood trauma, particularly emotional neglect, physical neglect, and sexual abuse, was higher in OCD patients with suicide attempts. This finding was consistent with previous studies (10,30-33). Khosravani et al. (10) compared 70 OCD patients with 60 healthy controls. The authors stated that sexual abuse and unacceptable thoughts may be associated with suicidal ideation. In this this study, as a limitation, a control group composed of such as OCD patients without a lifelong suicide attempt was not used. The strength of our study is that we compare it with OCD patients who had attempted suicide. In our study, a mild correlation was found between suicide probability and CTQ total score, emotional abuse, and sexual abuse, independent of BDI, YBOC and insight scores. It would be helpful for us to understand the dynamic mechanisms by integrating the variables, which may mediate between childhood traumas and OCD, into the study. Suicide risk is important in OCD, which is 10 times more suicidal than expected, (34) because it is significantly independent of psychiatric comorbidities (35). However, it is known that the suicide risk is associated with depression accompanying OCD (21). OCD is usually accompanied by other psychiatric disorders with comorbidity rates as high as $90 \%$ (1). The weakness of our study is that comorbid psychiatric disorders were not determined by structured interviews in our study. The association between CTQ and SPS was a positive correlation in our research. This result may indicate that childhood traumas in OCD predispose to suicide.

A statistically significant and mild correlation was observed between insight and SPS scores in our study. De Berardis et al. (36) indicated that OCD patients with the lack of insight may show an inflated responsibility associated with higher suicidal ideation. In another study, Gupta et al. (37) concluded that poor insight of certain aspects of the symptomatology may be linked to suicidal ideations. Although the insight assessment is based only on the YBOCS-11 item, the results of the present study are in line with the studies mentioned above. Therefore, we may suggest investigating suicidal ideation investigated, especially in the presence of lower insight in OCD. Extensive studies with specific psychometric instruments such as the Brown Belief Assessment Scale are needed to determine the relationship between low insight and suicide probability.

Examining the relationship between obsessive symptoms and childhood traumas, we found that aggression and sexual obsessions were more common in patients with suicide attempts. These results are consistent with the findings of other studies, in which current suicide ideas or suicidal behaviors in OCD are often associated with the severity of OCD symptoms such as aggression, symmetry or order and sexual or religious obsessions $(18,38,39)$. In OCD patients who attempted suicide, these dimensions may be associated with the feeling of guilt.

There were several limitations in this study. First, the cross-sectional design did not allow for causality to be studied, so longitudinal researches are needed. Second, while CTQ is a reliable and validated means of trauma evaluation, self- assessment can be prone to several biases, such as recall bias thanks to its retrospective qualities. Third, no specific psychometric instrument was used for assessed insight, as the corresponding item (item \#11) of the Y-BOCS was considered as a measure of insight level in the present study. Also, lifetime suicide attempt was not assessed using the Columbia-Suicide Severity Rating Scale, which is suitable for the assessment of suicidal ideation and behavior in clinical and research settings (40). However, considering the significant comorbidities of depression, substance use, and anxiety disorders, the fact that we did not follow such possible comorbid disorders in our study may probably be considered as a limitation. Another limitation of our study is that healthy controls were not included. Despite these limitations, the present study identified the risk factors associated with the suicidal tendencies in OCD patients, benefiting from further research.

The findings of this research on suicidal behavior in OCD patients may have some certain conclusions. Firstly, this research showed that childhood traumas may be a contributing factor for suicide probability and attempt in patients with OCD. Secondly, this research 
reveals that there is a higher risk of current suicide probability in OCD patients who had attempted suicide in the past. Based on our findings, we may therefore suggest that clinicians should always be cautious about investigating suicidal ideation in OCD, especially in the presence of childhood traumas and lower insight, and take appropriate measures to reduce the harm.

\begin{tabular}{|c|c|c|}
\hline \multicolumn{2}{|c|}{ Contribution Categories } & \multirow{2}{*}{$\begin{array}{l}\text { Author Initials } \\
\text { F.K. }\end{array}$} \\
\hline \multirow{3}{*}{ Category 1} & Concept/Design & \\
\hline & Data acquisition & F.K., A.A.U.K., F.D. \\
\hline & Data analysis/Interpretation & F.K., U.I. \\
\hline \multirow{2}{*}{ Category 2} & Drafting manuscript & F.K., A.D., U.I. \\
\hline & Critical revision of manuscript & A.D., A.A.U.K., U.I. \\
\hline Category 3 & Final approval and accountability & F.K., A.A.U.K., U.I., A.D., F.D. \\
\hline \multirow{2}{*}{ Other } & Technical or material support & F.K., F.D., A.A.U.K. \\
\hline & Supervision & A.D. \\
\hline
\end{tabular}

Acknowledgments: We wish to thank all patients and controls for participating in this study.

Ethics Committee Approval: The study project was approved by Süleyman Demirel University Faculty of Medicine Clinical Research Ethical Committee and informed consent was obtained from all participants after the study was fully explained to them (Date:21/03/2018, Number:71).

Informed Consent: Written consents were obtained from the patients who participated in the study.

Peer-review: Externally peer-reviewed.

Conflict of Interest: The authors report no conflict of interest regarding the publication of this paper.

Financial Disclosure: There is no financial support.

\section{REFERENCES}

1. Ruscio AM, Stein DJ, Chiu WT, Kessler RC. The epidemiology of obsessive-compulsive disorder in the National Comorbidity Survey Replication. Mol Psychiatry 2010; 15:53-63. [CrossRef]

2. Mayerovitch JI, du Fort GG, Kakuma R, Bland RC, Newman SC, Pinard G. Treatment seeking for obsessive-compulsive disorder: role of obsessive-compulsive disorder symptoms and comorbid psychiatric diagnoses. Compr Psychiatry 2003; 44:162-168.

3. Goodwin R, Koenen KC, Hellman F, Guardino M, Struening E. Helpseeking and access to mental health treatment for obsessivecompulsive disorder. Acta Psychiatr Scand 2002; 106:143-149.

4. Chong SA, Abdin E, Sherbourne C, Vaingankar J, Heng D, Yap M, et al. Treatment gap in common mental disorders: the Singapore perspective. Epidemiol Psychiatr Sci 2012; 21:195-202.

5. Nemeroff CB. Neurobiological consequences of childhood trauma. J Clin Psychiatry 2004; 65:18-28.

6. Breslau N. Epidemiologic studies of trauma, posttraumatic stress disorder, and other psychiatric disorders. Can J Psychiatry 2002; 47:923-929. [CrossRef]
7. Mathews CA, Kaur N, Stein MB. Childhood trauma and obsessive-compulsive symptoms. Depress Anxiety 2008; 25:742751. [CrossRef]

8. Carr CP, Martins CM, Stingel AM, Lemgruber VB, Juruena MF. The role of early life stress in adult psychiatric disorders: a systematic review according to childhood trauma subtypes. J Nerv Ment Dis 2013; 201:1007-1020. [CrossRef]

9. Lochner C, du Toit PL, Zungu-Dirwayi N, Marais A, van Kradenburg J, Seedat S, et al. Childhood trauma in obsessivecompulsive disorder, trichotillomania, and controls. Depress Anxiety 2002; 15:66-68. [CrossRef]

10. Khosravani V, Kamali Z, Jamaati Ardakani R, Samimi Ardestani $M$. The relation of childhood trauma to suicide ideation in patients suffering from obsessive-compulsive disorder with lifetime suicide attempts. Psychiatry Res 2017; 255:139-145.

11. Brander G, Pérez-Vigil A, Larsson H, Mataix-Cols D. Systematic review of environmental risk factors for obsessive-compulsive disorder: a proposed roadmap from association to causation. Neurosci Biobehav Rev 2016; 65:36-62. [CrossRef]

12. Carpenter L, Chung MC. Childhood trauma in obsessive compulsive disorder: the roles of alexithymia and attachment. Psychol Psychother 2011; 84:367-388. [CrossRef]

13. Caspi A, Vishne T, Sasson Y, Gross R, Livne A, Zohar J. Relationship between childhood sexual abuse and obsessivecompulsive disorder: case control study. Isr J Psychiatry Relat Sci 2008; 45:177-182.

14. Teicher MH, Samson JA. Childhood maltreatment and psychopathology: A case for ecophenotypic variants as clinically and neurobiologically distinct subtypes. Am J Psychiatry 2013; 170:1114-1133. [CrossRef]

15. Ludwig B, Roy B, Wang Q, Birur B, Dwivedi Y. The life span model of suicide and its neurobiological foundation. Front Neurosci 2017; 11:74. [CrossRef]

16. Joiner TE, Rudd MD. Intensity and duration of suicidal crises vary as a function of previous suicide attempts and negative life events. J Consult Clin Psychol 2000; 68:909-916. [CrossRef]

17. Angelakis I, Gooding P, Tarrier N, Panagioti M. Suicidality in obsessive compulsive disorder (OCD): a systematic review and meta-analysis. Clin Psychol Rev 2015; 39:1-15. [CrossRef]

18. Kamath P, Reddy YC, Kandavel T. Suicidal behavior in obsessivecompulsive disorder. J Clin Psychiatry 2007; 68:1741-1750.

19. Torres AR, de Abreu Ramos-Cerqueira AT, Torresan RC, de Souza Domingues M, Hercos AC, Guimarães AB. Prevalence and associated factors for suicidal ideation and behaviors in obsessive-compulsive disorder. CNS Spectr 2007; 12:771-778.

20. Dell'Osso B, Benatti B, Arici C, Palazzo C, Altamura AC, Hollander E, et al. Prevalence of suicide attempt and clinical characteristics of suicide attempters with obsessive-compulsive disorder: a report from the International College of ObsessiveCompulsive Spectrum Disorders (ICOCS). CNS Spectr 2018; 23:59-66. [CrossRef]

21. Breet E, Kidd M, Mcgregor NW, Stein DJ, Lochner C. Suicide ideation and attempts in obsessive-compulsive disorder. Ann Clin Psychiatry 2019; 31:192-199. 
22. Goodman WK, Price LH, Rasmussen SA, Mazure C, Fleischmann RL, Hill CL, et al. The Yale-Brown Obsessive Compulsive Scale. I. Development, use, and reliability. Arch Gen Psychiatry 1989; 46:1006-1011. [CrossRef]

23. Tek C, Ulug B, Rezaki BG, Tanriverdi N, Mercan S, Demir B, et al. Yale-Brown Obsessive Compulsive Scale and US National Institute of Mental Health Global Obsessive Compulsive Scale in Turkish: reliability and validity. Acta Psychiatr Scand 1995; 91:410-413. [CrossRef]

24. Matsunaga H, Kiriike N, Matsui T, Oya K, Iwasaki Y, Koshimune $\mathrm{K}$, et al. Obsessive-compulsive disorder with poor insight. Compr Psychiatry 2002; 43:150-157. [CrossRef]

25. Beck AT, Ward CH, Mendelson M, Mock J, Erbaugh J. An inventory for measuring depression. Arch Gen Psychiatry 1961; 4:561-571. [CrossRef]

26. Bernstein DP, Fink L, Handelsman L, Foote J, Lovejoy M, Wenzel $\mathrm{K}$, et al. Initial reliability and validity of a new retrospective measure of child abuse and neglect. Am J Psychiatry 1994; 151:1132-1136. [CrossRef]

27. Sar V, Ozturk E, Ikikardes E. Validity and reliability of the Turkish version of Childhood Trauma Questionnaire. Turkiye Klinikleri J Med Sci 2012; 32:1054-1063. [CrossRef]

28. Cull JG, Gill WS. Suicide probability scale. Western Psychological Services 1989; 12031:1997-2005.

29. Atli Z, Eskin M, Dereboy C. The validity and the reliliability of Suicide Probability Scale (SPS) in clinical sample. J Clin Psy 2009; 12:111-124.

30. Ay R, Erbay LG. Relationship between childhood trauma and suicide probability in obsessive-compulsive disorder. Psychiatry Res 2018; 261:132-136. [CrossRef]

31. Daray FM, Rojas SM, Bridges AJ, Badour CL, Grendas L, Rodante $D$, et al. The independent effects of child sexual abuse and impulsivity on lifetime suicide attempts among female patients. Child Abuse Negl 2016; 58:91-98. [CrossRef]
32. Wang YR, Sun JW, Lin PZ, Zhang HH, Mu GX, Cao FL. Suicidality among young adults: Unique and cumulative roles of 14 different adverse childhood experiences. Child Abuse Negl 2019; 98:104183. [CrossRef]

33. Paul E, Ortin A. Correlates of suicidal ideation and self-harm in early childhood in a cohort at risk for child abuse and neglect. Arch Suicide Res 2019; 23:134-150. [CrossRef]

34. Harris EC, Barraclough B. Suicide as an outcome for mental disorders. A meta-analysis. Br J Psychiatry 1997; 170:205-228.

35. Fernández de la Cruz L, Rydell M, Runeson B, D’Onofrio BM, Brander G, Rück C, et al. Suicide in obsessive-compulsive disorder: a population-based study of 36788 Swedish patients. Mol Psychiatry 2017; 22:1626-1632. [CrossRef]

36. De Berardis D, Serroni N, Campanella D, Rapini G, Olivieri L, Feliziani B, et al. Alexithymia, responsibility attitudes and suicide ideation among outpatients with obsessive-compulsive disorder: an exploratory study. Compr Psychiatry 2015; 58:82-87. [CrossRef]

37. Gupta G, Avasthi A, Grover S, Singh SM. Factors associated with suicidal ideations and suicidal attempts in patients with obsessive compulsive disorder. Asian J Psychiatr 2014; 12:140-146. [CrossRef]

38. Torres AR, Ramos-Cerqueira AT, Ferrão YA, Fontenelle LF, do Rosário MC, Miguel EC. Suicidality in obsessive-compulsive disorder: prevalence and relation to symptom dimensions and comorbid conditions. J Clin Psychiatry 2011; 72:17-26. [CrossRef]

39. Velloso P, Piccinato C, Ferrão Y, Aliende Perin E, Cesar R, Fontenelle $\mathrm{L}$, et al. The suicidality continuum in a large sample of obsessive-compulsive disorder (OCD) patients. Eur Psychiatry 2016; 38:1-7. [CrossRef]

40. Posner K, Brown GK, Stanley B, Brent DA, Yershova KV, Oquendo MA, et al. The Columbia-Suicide Severity Rating Scale: initial validity and internal consistency findings from three multisite studies with adolescents and adults. Am J Psychiatry 2011; 168:1266-1277. [CrossRef] 